\title{
The Impact of Computerized Information Systems on the Compliance of Internal Control Requirements According to ISA (315) in Jordanian Companies from the Perspectives of Their Employees
}

\author{
Loay S Al-Rahamneh ${ }^{1}$ \\ ${ }^{1}$ Shool of Business, University of Jordan, Jordan \\ Correspondence: Loay S Al-Rahamneh, Shool of Business, University of Jordan, Jordan. E-mail: \\ 1.rahamneh@ju.edu.jo
}

Received: July 4, 2016

Accepted: July 28, 2016

Online Published: August 25, 2016

doi:10.5539/ijef.v8n9p156

URL: http://dx.doi.org/10.5539/ijef.v8n9p156

\begin{abstract}
This study aimed at identifying the impact of computerized information system in compliance to internal control requirements according to ISA (315) in the Jordanian Companies from the Perspectives of their Employees. The study was implemented during the year 2015/2016, with sample that was chosen randomly and consisted of 50 employees who work for the Jordanian computer system companies. The results showed impacts of computerized information system on compliance to internal control requirements according to ISA (315). The researcher recommended the need to enact laws and develop new regulations that contribute in improving the effective use of computerized information systems at the Jordanian computer system companies.
\end{abstract}

Keywords: computerized information systems, internal control, ISA (315)

\section{Introduction}

The fields of computer science and accounting go hand in hand and complement each other because accounting and social sciences are influenced by social variables that cause rapid changes. The most important variables that affect both computer science and accounting include: the developments in information and communication technology; the accountants are supposed to perform their tasks accurately through the use of accounting software and data processing. In addition, implementing financial transactions, bank accounting effect the use of computer technology in the accounting and auditing companies.

The information technology (IT) solves problems through logical thinking as they develop understanding and awareness about many social and economic aspects. In addition, (IT) contributes in the development humanity and culture, helps in resource management and affects social, moral, economic and political relations as well as affecting job performance. In return, this contributes in the effective communication and solves problems whenever they occur. Moreover, IT can develop the employees' skills and in doing accurate tasks that enhance the spirit of creativity and innovation.

On the other hand, IT represents the main priority for the IT sector to facilitate services, improves productivity and integrates all operators of systems and institutions in providing hardware and technical applications. Furthermore, internet has contributed significantly in providing the necessary infrastructure to provide databases.

Management of information systems mainly is linked to information technology, which can be defined as the structural configuration of integrated and interactive of machinery, equipment, software and manpower. This ensures data collection and processing in order to provide the necessary information (to the beneficiaries, in terms of storage, updating and retrieval of information) on the right time, with less cost and high quality for the internal environment of the organization and for the surrounding environments. Conversely, this will facilitate the task of administrators at all levels in the decision-making to complete all administrative functions and to use of such information appropriately (Al-Mamary, 2014).

Accounting information system contains components that include several software and bank accounting information. Such systems are specifically designed to manage and handle the financial data which are introduced through the accounting software in the aim to extract and prepare reports, documents, financial transactions and other necessary papers needed by all beneficiaries and stakeholders (Karim, 2011). 
Furthermore, information technology plays a significant role in the analysis of problems and decision making process in the industrial and service organizations. Study results show that such benefits are based on the use of computer information system that help reduce the number of computerized operations, increase and enhance the process of regulatory decision-making by facilitating communication between the stakeholders in and organization (Laudon \& Jane, 2009).

In this context, there are four basic aspects that help organizations apply computerized information systems, namely: the physical environments, human, technical and administrative (Laudon \& Jane, 2009):

First: the physical requirements: These represent the devices, networks, information systems including the output and input units and CPUs. The physical requirements help an organization to perform business and accounting transactions, the processes of planning and production control, facilitate the control of property on regular basis, preparing special reports, help the managers take necessary decisions and provide operational indicators about the current and future position of the business as well as the expected changes and developments.

Second: the technical requirements: use of information systems and techniques lead to recognizing and analysis of problems through a high quality technology programs. However, the use of information technology in the Jordanian insurance sector have enhanced efficiency and increased the effectiveness decision makers. Moreover, the use of information technology saves time, effort and they play a positive role in the effectiveness of decisions taken by an organization. Information systems, when linked to business networks and information technology systems, result in using advanced infrastructure and computer applications, which facilitate finding many solutions for the problems that an organization may encounter during its business.

Third: human requirements: in order to improve and develop employees' performance, they need training and development program that result in the identification of projects, weakness and strength points, knowledge of how best to regulate the duties and tasks of the employees as well allowing the staff to find mechanisms to prevent taking mistaken and costly decisions.

Fourth: the administrative requirements: Many studies showed that there is a strong relationship between the computerized information systems and the distribution of authorities between various units of an organizational. Research found a link between planning, activities and distribution of authorities within the various administrative units. Accordingly, decentralization helps to speed up the decision-making process. However, there was no relationship between the quality of the decisions taken, control of computerized information and quality of the activities implemented. The studies did not show a relationship between the distribution of authorities within the organizational units, the financial resources and replacement of the machines and equipment.

In return, this enables an organization to use computerized information systems in order to improve work at all levels and particularly auditing and accounting systems. These tasks are considered among the first concerns and priorities of the administration. In general, the level of performance results in improving and raising the staff performance, provide better, faster and high quality services to satisfy the customers' needs.

In light of the emergence of technology development and improvement in control systems, the use of computerized information systems has become an integral part the internal audit not only in the Jordanian shareholding companies, but also on an international level. Lack of information and the treatment methods may prevent or impede access to such dynamic systems since they rely on scientific methods during various processes such as: preparation, implementation and modification (Cohen \& Simnett, 2015).

The Information Systems Audit and Control measures have the acronym ISACA, this term reflects the broad range of IT governance professionals it serves and the topics to be dealt with while using technology for auditing. Such technology includes: computer assisted audit techniques-CAAT, virtual machine technology audit, IT and cyber-commerce, accounting reporting, IS forensic accounting, information systems auditing, internal control evaluation, application control tests, COBIT, VaLIT, cloud computing, compliance auditing, continuous auditing, E-commerce auditing, sarbanes-Oxley compliance, fraud detection, audit risk, valuation, artificial intelligence, PCI compliance, auditing claims, XBRL ... etc..

Information Systems Auditing in the field of applied social science supports all information users, offers data, knowledge and methods pertaining to the IT organizational control, review of hardware and infrastructure, security control, system development, maintenance and documentation controls.

The use of IS Audit to support financial audit ISA 620 - relies mostly on the tasks of an auditor's expert. Such tasks should be stated clearly, utilize the services of audit specialists with the participation of all management 
levels. Generally, as a member of the engagement team, he tests the general controls and also performs substantives tests. Moreover, an expertise of the IS Auditor deals with analytical procedures that are implemented for the services provided by an independent auditing.

All of the above mentioned topics could be analyzed focusing two perspectives: (a) Governance theories agency theory, institutional theory and resource dependence; and (b) code - regulation and compliance, IT risk management, industry approach to IT and ISA and potential sanctions against CEOs. Thus, there is a concern about the use of these technologies by the information systems auditors. Those efforts are directly related with the auditors' capacities and limitations, choosing the right technology that would show befitting characteristics, skills that could safely comfort stakeholders, or define standards for information confidence and consequently, improve the living standards of the whole society. Within the pool of ISA standards IT and Audit concepts are made up of several threads which lead to different constituents but to intend to achieve the same comforting directions and objectives.

In general, computerized information systems have an impact on internal controls, especially through the standard (ISA 315). This standard aims at identifying and assessing the risks of distortion by understanding the entity/ company. In this regard, the Environment Committee states that the auditors need to understand the internal controls applied in a facility. To help achieve this process, there are five components of internal control system, namely: (Wei-hua, 2011):

- Environment controls;

- Facility risk assessment process;

- Information systems;

- Oversight activities;

- Monitoring controls.

Environment controls: this includes a referee computerized organization to the control environment. It largely focuses on the attitudes, awareness and actions implemented by those who are responsible for the design and implementation of the business.

Risk assessment process: a basis of how to determine the risks that must be managed and handled. These processes differ greatly depending on their nature, details and the consequences of the risk.

Information Systems: all procedures and records that are designed.

Control of activities: noting and observing all policies and procedures. Such activities are designed to ensure the good implementation of computerized activities throughout the organization.

Monitoring controls: these intend to continuously assess the effectiveness of controls and take the necessary corrective actions.

Computerized information systems: the basic part and important administrative information in the economic unit system which relates to: inventory. Financial data compiled from external resources within the economic department, using and transferring data into financial information for users outside and inside the unit.

Internal control: the ways, means and procedures adopted by the directors of a corporation or a group of economic unit for multiple purposes, including the protection of funds and assets, ensure adherence with the administrative policies and plans drawn to achieve the main and sub-goals relating to the financial and administrative systems no to forget the technical activities.

(ISA 315): a standard for identifying and assessing the risks that allow specialists understand the entity. The US Environment Committee states that the auditors need to understand the internal control of the facility

The main objective of this study is to identify the "The Impact of Computerized information systems on Compliance to internal Control requirements according to ISA (315)". In addition, the study aims at achieving the following sub-objectives:

- Identify the level of application of computerized information systems in the Jordanian Companies from the perspectives of their employees.

- Uncover differences for the application of computerized information systems to the Jordanian Companies from the perspectives of their employees, due to gender (male, female)?

- Examine whether there are differences for the application of computerized information systems to the Jordanian Companies from the perspectives of their employees, due to the employees' scientific expertise 
(less than five years, from (5-10) years, more than ten years)?

- Check if there are differences for the application of computerized information systems to the Jordanian

Companies from the perspectives of their employees due to age.

Notes from the previous presentation the importance of the subject of the study, and through this study will be a set of findings and recommendations aligned with the aims and purposes of the study mode.

\subsection{Introduce the Problem}

The challenges and pressures facing businesses are growing one day after the other. These changes include rapid developments in technology, computer systems, hardware, software and other devices. To complete, a company should deal with many challenges and cope with all technological and IT developments. In addition, a good and successful company has to use the latest scientific developments in computer systems and technology information and apply computerized information systems in order to improve internal Control requirements according to ISA (315).

Accordingly, this study sheds light on some problems facing the Jordanian companies in field of internal audits that affect the company's activity due to:

1- Lack of enough knowledge about the variables that impact various activities and the external and internal scope of control processes.

2- Non-continuous of information flow which in turn, affects the performance of the sub-systems that are applied within the organization.

3- The methods that are used for the preparation and amendment of data processing systems are inappropriate.

4-The application of estimation methods and forecasting future incidents without using scientific methods.

5- Deficiencies in the use of computer systems - in case if they are available in the facility which prevent an organization from achieving its main objective of (a database facility).

In other words, the problem of the study can be clarified through answering the following questions:

The first question: Are there any significant statistical differences for the application of computerized information systems in the Jordanian companies from the perspectives of their employees, which can be attributed to gender?

Second question: Are there any significant statistical differences for the application of computerized information systems in the Jordanian companies from the perspective of their employees due to scientific expertise?

Third question: There are no significant statistical differences for the application of computerized information systems to the Jordanian Companies perspective of their employees due age.

Forth question: are there any impacts for computerized information systems on compliance to internal control requirements according to ISA (315) from the perspectives of the employees of the Jordanian companies?

The objectives of the study therefore:

\section{A-Theoretical importance}

The significance of the study is embodies through highlighting the theme "The Impact of Computerized information system on Compliance to internal Control requirements according to ISA (315)". In addition, the study will present the results and recommendations that enrich the subject. On the other hand, this study will identify all obstacles that hinder the implementation of computerized information systems in the Jordanian Companies

\section{B-Applied Popularity}

The present study will be useful for the following parties:

- The employees who work for the Jordanian companies as such companies can benefit from this study by identifying the Impact of Computerized information system on Compliance to internal Control requirements according to ISA (315).

- Managers: who can develop policies and strategies that improve the effective use of computerized information systems.

- Researchers: to identify the challenges, difficulties, implications, findings and to develop other variables pertaining to the subject of the study. 


\subsection{Describe Relevant Scholarship}

The researcher arranged the studies relating to the subject in a descending order:

Joshua OnomeImoniana (2015): The study aimed at investigating the role of IS auditor in the lens of Resilience test in IT risk Management Assurance. The study has its relevance where the implications of abandonment of ISA 401 or suppression ISA 620 in auditing engagement particularly, when one reflects upon the current complexity from use of digital technologies and the questionings arising from the recent financial scandals. Based on the study analysis, the independent auditors need to rethink about the use of ISA 401 and ISA 620 in order to ensure the true rule of quality of financial statement audit.

Navaz, 2013, conducted a study that aimed to examine the concepts and applications of management information systems. In addition, the study intended to investigate the integrated system so as to provide information that support planning, organization, control of functions in the special reports issued by the middle management. Those systems include all information and communication channels. Information systems consist of all items needed in the collection and dissemination of data and information. This usually involves making changes in the hardware, channels, software, people, data, information and communication styles and methods. The results of the study did not show significant statistical differences that are attributed to gender, age and system operation including data collection, processing, storage and retrieval of information and data sets (e.g. administrative reports).

- Nayak et al. (2012) implemented a study that aimed at examining the efficiency of management information systems for the decision making process. In addition, the study investigated the decision-making process which is considered as an integral part of the work of any corporation. To facilitate the decision-making process in this world of competition than ever, it is imperative that managers should have the right information at the right time to bridge the gap between the needs and expectations. Another objective of the study was to know whether information systems facilitate a better flow of information management and create a good understanding of management information systems that are used in the organization at all levels. In return, this provide managers at all levels who use IS with a good ability to take decisions, planning and implementation and control of the programs. Information management system has many roles to perform, such as supporting the decisions taken, monitoring the performance and careers. To gain a more detailed understanding of a particular function of the company, there is a need to know and examine the uses and benefits of management information systems with regard to the physical components of the company. The results showed that MIS and facilitated all of such tasks and functions, helps in the decision making process, synchronize the flow of information in the organization as the management felt it plays and important role in increasing the performance of both the staff and the departments of the company.

Salehi and Abdipour (2011): a study which aimed at studying the barriers that hinders the implementation of accounting information system in Tehran: a Case of Listed Companies in Tehran Stock Exchange. The population of the study population consisted of 406 companies from 36 industry sectors with a sample that consisted of 100 companies listed on Tehran Stock Exchange. A questionnaire was used to achieve the purpose of the study. The results showed that the accounting information systems are important in all companies. In addition, the study shed light on a number of obstacles that prevent the application of accounting information in the Tehran stock exchange, namely, (middle management, human resources, organizational structure, environmental factors, financial issues and the organizational culture).

AL-Eqab and Ismail (2011): examined the contingency factors and accounting information system design in the Jordanian companies. The purpose of the study was to uncover the factors that contribute to the design of the accounting information systems. The sample consisted of 220 companies listed on the Amman Stock Exchange in Jordan. For the purposes of the study, a questionnaire was used. The results showed positive effects on the four dimensions of the development of information technology (the technological, information, functional and administrative). Moreover, the study showed a relationship with significant statistical differences between the dimensions of business strategies (cost, leadership, differentiation and innovation) and the design of accounting information systems. However, no differences that can attribute to (gender, experience, and age) were mentioned. In addition, there were no significant statistical effects between the environmental conditions and the evolution of the design of accounting information systems, whereas the development of administrative, information and functional management technology are more important than technological development in influencing the design of the accounting information system.

Wei-hau (2011): examined the precaution of enterprise internal control under the ERP System". Moreover, the study aimed at presenting the risks associated with internal control system and how to avoid them in light of the 
organization's resources and the planning systems in force. The results showed that there are key factors for the internal control of companies, namely: environment, risk assessment, control activities, information and communication systems and efficient observation. The sample included a construction company in China. The study concluded that the background information and information of customers and suppliers, as well as choosing the (ERP) system promote awareness of the risks of enterprise and strengthen the supervision by the internal auditing unit.

Soral and Jain (2010): This study aimed at examining the impact of ERP system on auditing and internal control. In addition, the study aimed to demonstrate the impact of systems (ERP) to scrutinize the organizations process and the focus was to discuss whether there are any changes in the auditing process in place to systems organizations (ERP) on the internal control system of the Organization. This was achieved through the use of a questionnaire that was sent via e-mail, as well as by conducting structured interviews during the initial data collection phase. The sample of the study consisted of (22) companies in India where the researchers tested the statistical results of the questionnaire. In addition, the results indicated that there is a large-scale work for future studies that should examine the impact of the organization's resources and the effect of such resources on planning the audit and internal control system of systems.

The researcher concluded with a number of conclusions, namely: the internal auditor should be aware of the risks in the organization in case of applying ERP systems because of the nature of the complexity of these systems, as these systems impose a critical need for stronger internal control system, and the need to use modern technology which contribute in raising the quality of audit systems and internal controls in organizations.

Nayak et al. (2010): The study examined the effectives of management information system for the successful decision making process and the decision-making process is an integral part of the work of any division in an organization. The results showed that the better flow of information management facilitates adequate information systems (MIS). Moreover, the study showed that linking data (information) and making them available to the managers at all levels help them in the decision making process, planning and implementation of programs, and control.

Edwards et al. (2010): This study examined information technology and the relevant activities of internal auditors. Furthermore, the study aimed at: First, identify the role of the internal control system as one of the subsystems component of the accounting system to make sure: the health and safety input accounting system, and the statement of the impact of organizational factors in the efficiency and effectiveness of the control system, and the efficiency of electronic data processing and computer systems and application software and systems protection, databases and other elements of the accounting system. Second, discussing the importance of the audit, internal control and the role of information provided by the internal auditor in that: to achieve the company's goals, and error detection, treatment and prevention of fraud and fraud and ensure appropriate protection for the company's assets and property and reduce Olney risks exposed Leaders size by focusing on tasks and audit, internal control and test the efficiency and effectiveness of the internal control system, both regulatory and practical. The study was to conduct a general survey included internal auditors in banks and banking institutions in the United States for the year (2010). The researchers found a number of findings, including: the Control and Internal Audit used in these banks systems contribute to adding new value to the organization and help achieve the goals of the business plans and oversight reports and audits, including their recommendations to fix errors and business development.

Sayana et al. (2008): examined the use of CAATs to support IS audit" and to strengthen the process of auditing of the accounting information systems using auditing methods of computer-aided-mail. The researchers applied the descriptive approach in the formulation of research and by reference to the related literature and scientific books in Britain. The study showed that the use of audit computer aided mail methods strengthen the process of auditing of the accounting information through electronic systems. The results showed that data analysis, evaluation of network security and assess the security of database management systems, and test programs and codes highly improve the performance of both the auditors and employees of an organization.

Burton (2007): The study examined the effect of information technology and activities related to the internal auditors and to evaluate the information systems and technology in terms of efficiency, effectiveness and the economics of information economies systems, related activities, auditing and the internal controls. The sample consisted of (379) internal auditors in the United States and the researcher used a questionnaire which was distributed to (102) auditor to identify the percentage (27\%) off the total population who received the questionnaires. The answers of the sample about the role of systems and technology of accounting information in the protection of property through the provision of procedures and controls security and appropriate protection 
were positive and for the interest of their organization. The results showed a need to raise the level of efficiency of the systems and technology of accounting information, conducting maintenance operations and make improvements on equipment, devices and programs to make the best of business and to enforce general policies, guidelines and objectives that enhance corporate performance.

\section{The researcher's comments on the previous studies:}

This study is distinct from previous studies in terms of the following:

- It will examine the employees' attitudes and perspectives in the Jordanian companies.

- This study is a descriptive and analytical one as the researcher will develop a measurement tool that will be distributed to the employees who represent the population of the Jordanian companies.

- According to the researcher's knowledge, this is only study one that examines this topic in specific.

\subsection{Hypotheses}

The study applies the following (zero) hypothesis:

First hypothes is: There are no differences at the level of significance $(\alpha \leq 0.05)$ for the application of computerized information systems to the Jordanian Companies from the perspectives of their employees, due to gender.

Second hypothes is: There are no differences at the level of significance $(\alpha \leq 0.05)$ for the application of computerized information systems to the Jordanian Companies from the perspectives of their employees, due to years of experience.

Third hypothes is: There are no differences at the level of significance $(\alpha \leq 0.05)$ for the application of computerized information systems to the Jordanian Companies from the perspectives of their employees, due to age.

Fourth hypothes is: There are no impact at the level of significance $(\alpha \leq 0.05)$ on Computerized information systems on Compliance to internal Control requirements according to ISA (315) from the perspectives the employees of the Jordanian companies.

\section{Method}

It was used descriptive and analytical approach that deals with data collection, analysis and interpretation in addition to the statistical treatment of the variables and their linkages, as well as analysis and interpretation of results by their relevance.

\subsection{Identify Subsections}

The study population consisted of a group of workers at the Jordanian Companies. The study sample consisted of 50 of the workers at the Jordanian Companies, during the year 2015/2016; the sample was chosen randomly.

\subsection{Participant (Subject) Characteristics}

The following table shows the characteristics of the study sample and described, in terms of (gender, experience and ages).

1) Gender

Table 1. Demographic characteristics of study sample (gender)

\begin{tabular}{lcc}
\hline Gender & Frequency & Percentage \\
\hline Male & 30 & $60.0 \%$ \\
Female & 20 & $40.0 \%$ \\
Total & $\mathbf{5 0}$ & $\mathbf{1 0 0 . 0} \%$ \\
\hline
\end{tabular}

Table 1 shows that $60.0 \%$ of respondents are males and the rest are females.

2) Experience 
Table 2. Demographic characteristics of study sample (experience)

\begin{tabular}{lcc}
\hline Experience & Frequency & Percentage \\
\hline less than 5 years & 23 & 46.0 \\
from 5 to 10 years & 12 & 24.0 \\
from 11 to 15 years & 5 & 10.0 \\
16-20 years & 5 & 10.0 \\
More than 20 years & 5 & 10.0 \\
Total & $\mathbf{5 0}$ & $\mathbf{1 0 0 . 0 \%}$ \\
\hline
\end{tabular}

The most percent of experience (46.0\%) was for respondents whom experience (less than 5 years), as shown in Table 2 and around (24.0\%) of respondents have experience (from 5 to 10 years), and $10.0 \%$ are (from 11 to 15 years), and (16-20 years) are 10.0\%, and the rest are (More than 20 years).

3) Age

Table 3. Demographic characteristics of study sample (age)

\begin{tabular}{lcc}
\hline Age & Frequency & Percentage \\
\hline less than 25 year & 7 & $14.0 \%$ \\
from 25 to 34 year & 6 & $12.0 \%$ \\
from 35 to 44 year & 7 & $14.0 \%$ \\
more than 45 year & 30 & $60.0 \%$ \\
Total & $\mathbf{5 0}$ & $\mathbf{1 0 0 . 0} \%$ \\
\hline
\end{tabular}

It was found that (14.0\%) of the sample are (less than 25 year old), (12.0\%) of them are between (25 to 34 years), (14.0\%) of them are (from 35 to 44 year), (60.0\%) of them are (more than 45 year).

\subsection{Sampling Procedures}

Been used descriptive and analytical approach to the relevance of the objectives of the study and its objectives, as has been sampling the manner of random, sample was selected (according to estimates by the equation Sekaran and Bougie (2013)) This study used the Statistical Package for Social Sciences software system (version twenty ten) (Statistical Package for Social Sciences -SPSS, ver20), in order to order to reach the goals and objectives of this study.

\subsubsection{Sample Size, Power, and Precision}

The study sample consisted of (50) work (In the accounting department) in the Jordanian computer system companies, during the year 2015/2016; the sample was chosen randomly.

\subsubsection{Measures and Covariates}

The study of the following actions:

- The preparation and processing of the study "resolution" tool, has also been presented to a group of arbitrators in Jordanian universities, and this shows the Appendix (1) identification of the study.

- The researcher extracted semantics validity and reliability study tool.

- The researcher distributed questionnaire on a group of workers in Jordanian businesses.

- The researcher collecting, validating tool ruled out questionnaires non-approval of the terms of the study.

\subsubsection{Research Design}

In order to obtain information and data; researcher depends on the construction and development of Scale (a questionnaire), a standard tool has been relying on to build reviews and studies and a former literature, and takes into account the build to make effectors conscious of its goal and components, accuracy and clarity and uniformity in the manner that serves the goals and objectives of the study. The way that serves the goals of the study questions.

The researcher presented a questionnaire study on a group of university professors, and that they have to amend some paragraphs of the resolution, and the number of paragraphs of the resolution to (19) paragraph. In order to achieve the purposes and objectives of the study questionnaire was designed based on the model Likert (Scale 
Likert) Quintet, and consisted of two parts, which included the first part on the personal information data, and the second part consisted of paragraphs on the subject of the study, has been grading standard answer for each paragraph in accordance with the Likert scale Quintet and identified five levels: Strongly agree (5 degrees), Agree (4) Neutral (3 degrees) Disagree (degrees) and Strongly Disagree (one degree).

\subsubsection{Experimental Manipulations or Interventions}

The study variables in Computerized information systems (independent variable), and Internal control requirements according to ISA (315) (dependent variable), demographic variables of (gender, age, experience).

In order to verify the stability of the questionnaire was conducted test (Cronbach's alpha) to measure the stability of the measuring instrument reaching internal consistency of the proportion of the questionnaire $(\alpha=85.5 \%)$ which is an acceptable percentage for the purposes of the study.

Through previous procedures to ensure the veracity of the study tool and determine the sample study, questionnaires were distributed to the sample in question, and then unloaded the study sample on a computer answers, and analyze data using statistical analysis system (Statistical Package for Social Sciences -SPSS. Ver20).

\section{Results}

The study using descriptive analytical approach in order to achieve the objectives of the study, showing that there is a (Impact of Computerized information systems on the Compliance of internal Control requirements according to ISA (315) in Jordanian Companies from the Perspectives of their Employees), and can explain these results through the following view:

The mean of the scale (3) has been used as a standard for judgment. If the result is lower than (3), this indicates that the phrase was not good. However, if the result is higher than (3) indicating to a good result:

\section{The First Section: material requirements}

Table 4 shows the mean, standard deviation and the degree of approval for each paragraph on this Field.

Table 4. Means and standard deviation of the first section (material requirements)

\begin{tabular}{llrr}
\hline Questions & Mean & Std. Deviation & N \\
\hline First Section: material requirements & & \\
1. The Jordanian companies develop computer hardware to keep pace with the growing demands and & 3.68 & 1.26 \\
needs of customers. & 3.43 & 1.36 & 50 \\
2-There are available appropriate accessory for computer hardware that facilitate the nature of work. & 3.31 & 0.18 & 50 \\
3- Modern and high speed and quality are used in the Jordanian companies. & $\mathbf{3 . 4 7}$ & $\mathbf{0 . 9 3}$ & 50 \\
\hline \multicolumn{1}{c}{ Total } & &
\end{tabular}

Table 4 shows that the mean average for the answers about the "First Section: material requirements" (3.47), was "Agree" and the standard deviation was (0.93).

As Shown in Table (4-5), there were positive attitudes toward the above questions because their mean were greater than the mean of the scale (3), but in different percentage.

The phrase which gained the highest mean in this Section is number (2) "There are available appropriate accessory for computer hardware that facilitate the nature of work". This means reached (3.68) and the standard deviation was (1.26).

This means was the lowest and amounted to (3.31) regarding the phrase number (3) "Modern and high speed and quality are used in the Jordanian companies".

\section{The second Section: The Technical Requirements}

Table 5 shows the mean, standard deviation and the degree of approval for each paragraph of this Section. 
Table 5. Means and standard deviation of second section (the technical requirements)

\begin{tabular}{|c|c|c|c|}
\hline Questions & Mean & Std. Deviation & $\mathbf{N}$ \\
\hline \multicolumn{4}{|l|}{ Second Section : The Technical Requirements } \\
\hline 4- Jordanian Companies have a master database. & 3.63 & 1.21 & 50 \\
\hline 5- Availability of ready- made latest versions of the software. & 3.42 & 1.11 & 50 \\
\hline $\begin{array}{l}\text { 6- Programs are automatically continuously developed continuously in collaboration with programming } \\
\text { companies. }\end{array}$ & 3.33 & 1.18 & 50 \\
\hline 7-Latest versions of operating systems are available. & 3.72 & 1.23 & 50 \\
\hline 8- Availability of the software needed to do the tasks of the job help in performing administrative tasks. & 3.26 & 1.11 & 50 \\
\hline 9-Software security and protection available on modern computers. & 3.04 & 1.25 & 50 \\
\hline 10- Jordanian Companies maintains a presence backup databases for all information & 3.29 & 0.24 & 50 \\
\hline Total & 3.38 & 1.04 & 50 \\
\hline
\end{tabular}

The previous table shows that the Mean average for the answers of the respondents was about the "second section: The Technical Requirements" (3.38), "Agree" And the average standard deviation was (1.04).

As Shown in Table 5, there were positive attitudes toward the above questions because their mean was greater than the mean of the scale (3), but with a different percentage.

The phrase which is the high mean in this Section is number (7) "Latest versions of operating systems are available", This means amounted to (3.72) and the average standard deviation was (1.23).

This means gained the lowest level and reached (3.29) in terms of phrase number (10) "Jordanian Companies maintains a presence backup databases for all information".

\section{Third Section: human requirements}

Table 6 shows the mean, standard deviation and the degree of approval for each paragraph of this section.

Table 6. Means and standard deviation of the third section: human requirements

\begin{tabular}{|c|c|c|c|}
\hline Questions & Mean & Std. Deviation & $\mathbf{N}$ \\
\hline \multicolumn{4}{|l|}{ Third Section: human requirements } \\
\hline $\begin{array}{l}\text { 11-There is a special division in the Jordanian Companies for the maintenance of computerized } \\
\text { information systems. }\end{array}$ & 3.23 & 1.22 & 50 \\
\hline 12-There are specialists who can provide solutions to the problems of frequent users. & 3.11 & 1.61 & 50 \\
\hline Total & 3.17 & 1.41 & 50 \\
\hline
\end{tabular}

From the above table you can see that the Mean average for the answers of the respondents was about the "Third Section: human requirements" (3.17), "Agree" And the average standard deviation was (1.41).

As Shown in Table 6, there were positive attitudes towards the above questions because their mean was greater than the mean of the scale (3), but in different percentage.

Phrase number (11) had the highest mean in this Section is number "There is a special division in the Jordanian Companies for the maintenance of computerized information systems" The average of this means amounted to (3.23) while the standard deviation was (1.22).

The means that had the lowest degrees amounted to (3.11), which relate to the phrase number (12) "There are specialists who can provide solutions to the problems of frequent users".

\section{Fourth Section: the administrative requirements}

Table 7 shows the mean, standard deviation and the degree of approval for each paragraph of this section. 
Table 7. Means and standard deviation of fourth section: the administrative requirements

\begin{tabular}{|c|c|c|c|}
\hline Questions & Mean & Std. Deviation & $\mathbf{N}$ \\
\hline \multicolumn{4}{|l|}{ Fourth Section : the administrative requirements } \\
\hline $\begin{array}{l}\text { 13- Availability of computerized information systems provide all required information in the various } \\
\text { sections of Jordanian Companies. }\end{array}$ & 3.53 & 1.19 & 50 \\
\hline $\begin{array}{l}\text { 14- Availability of computerized information systems provide employees with all required information } \\
\text { in a timely manner. }\end{array}$ & 3.42 & 1.22 & 50 \\
\hline 15- Information is constantly updated to satisfy the employees' needs. & 3.24 & 1.23 & 50 \\
\hline Total & 3.39 & 1.21 & 50 \\
\hline
\end{tabular}

The previous table shows that the Mean average for the answers of the respondents was about the "fourth section: the administrative requirements" (3.39), "Agree" And the average standard deviation was (1.21).

The phrase which is the high mean in this Field is number (13) which said (Availability of computerized information systems provide all required information in the various sections of Jordanian Companies), whereas the mean was (3.53) and the average standard deviation was (1.19).

This means was the lowest and reached (3.24) to the phrase number (15) which said (Information is constantly updated to satisfy the employees' needs).

Fifth Section: Internal control requirements according to ISA (315)

Table 8 shows the mean, standard deviation and the degree of approval on each paragraph.

Table 8. Means and standard deviation of the fifth section

"Internal control requirements according to ISA (315)"

\begin{tabular}{|c|c|c|c|}
\hline Questions & Mean & Std. Deviation & $\mathbf{N}$ \\
\hline \multicolumn{4}{|l|}{ Fifth Field: Internal control requirements according to ISA (315) } \\
\hline 16- Standards contribute in the control of the surrounding environment. & 3.84 & 1.51 & 50 \\
\hline 17- It helps the organization in the process of risk assessment process. & 3.65 & 1.45 & 50 \\
\hline 18- The standard identification support information system. & 3.72 & 1.39 & 50 \\
\hline 19- The identification of standards control activities and monitoring of controls. & 3.71 & 1.45 & 50 \\
\hline Total & 3.73 & 1.45 & 50 \\
\hline
\end{tabular}

The previous table shows that the Mean average for the answers of the respondents was regarding the Fifth Section, "Internal control requirements according to ISA (315)" (3.58), "Agree" and the average standard deviation was (1.25).

The phrase which is the high mean in this Field is number (16) which said (Standards contribute in the control of the surrounding environment). Whereas its means was reached (3.84) and the average standard deviation was (1.51).

This indicates that the lowest results reached (3.65) to phrase number (17) "It helps the organization in the process of risk assessment process".

\subsection{Recruitment}

Several foundations have been identified in order to achieve the purposes of the study, which is as follows:

Temporal: This study was implemented in the year 2015 and did not include previous years.

Spatial: the study was limited to examine the employees' perspectives who only work for the Jordanian companies without dealing or investigating other company employees in the Arab, regional, western or American countries...

Human: a questionnaire will be distributed to a sample of employees who work for the Jordanian companies.

\subsection{Statistics and Data Analysis}

The use of statistics in order to achieve the objectives of the study, and the study using the statistical software (SPSS), Twentieth version, and also used the Excel program (2010). 


\subsection{Ancillary Analyses}

The use of simple statistics of (Mean and standard deviations, and frequencies and percentages), was also used statistical analysis of (t-test, as well as the variance).

\subsection{Participant Flow}

Been used an experimental sample of employees of enterprises, estimated at about (10) employee in order to identify the extent to study the stability of (pilot study), it shows that the reliability coefficient (Cronbach's alpha) for the sum of variables was (85.5\%) which led to the completion of the study. this was between (Miller, 2013) that if the reliability coefficient of more than $(60 \%)$ it is considered highly reliable coefficient, and therefore are considered highly stable this study transactions.

\subsection{Intervention or Manipulation Fidelity}

This study is based on two hypotheses namely: the null and the sub-set assumptions, which are:

\section{First hypothesis:}

First hypothesis $\mathbf{H 0}_{1}$ : There are no differences at the level of significance $(\alpha \leq 0.05)$ for the application of computerized information systems to the Jordanian Companies from the viewpoint of its workers due to gender.

In order to validate the hypothesis (first sub-hypothesis) test was performed (Independent Samples T-Test), the Table 9, show that.

Table 9. Test of hypothesis (first hypothesis)

(Independent Samples T-Test)

\begin{tabular}{|c|c|c|c|c|c|c|}
\hline Section & $\begin{array}{l}\text { Mean } \\
\text { (male) }\end{array}$ & $\begin{array}{c}\text { Male } \\
\text { Standard Deviations }\end{array}$ & $\begin{array}{c}\text { Mean } \\
\text { (Female) }\end{array}$ & $\begin{array}{c}\text { Male } \\
\text { Standard Deviations } \\
\end{array}$ & $\begin{array}{c}\text { Value } \\
\text { (t) }\end{array}$ & SIG \\
\hline First Section: material requirements & 3.4249 & .9555 & 3.7765 & .9331 & -1.127 & .533 \\
\hline Second Section: The Technical Requirements & 3.2415 & 1.0445 & 3.4688 & 1.0110 & .877 & .726 \\
\hline Third Section: human requirements & 3.3256 & 1.0668 & 3.5226 & 1.0836 & 1.213 & .741 \\
\hline $\begin{array}{l}\text { Fourth Section: the administrative } \\
\text { requirements }\end{array}$ & 3.6259 & 1.0889 & 3.4118 & 1.1245 & .913 & .744 \\
\hline
\end{tabular}

Table 9 shows that there are no significant statistical differences at $(\alpha \leq 0.05)$ level between for the application of computerized information systems to the Jordanian Companies from the viewpoint of its workers depending on the demographic variables (gender).

\section{Second: hypothesis}

$\mathbf{H O}_{2}$ : There are no differences at the level of significance $(\alpha \leq 0.05)$ for the application of computerized information systems to the Jordanian Companies from the viewpoint of its workers due to experience.

In order to validate the second hypothesis a test was performed (One Way ANOVA), The Table 10 shows that result.

Table 10. Test of hypothesis (second sub-hypothesis) (one way ANOVA)

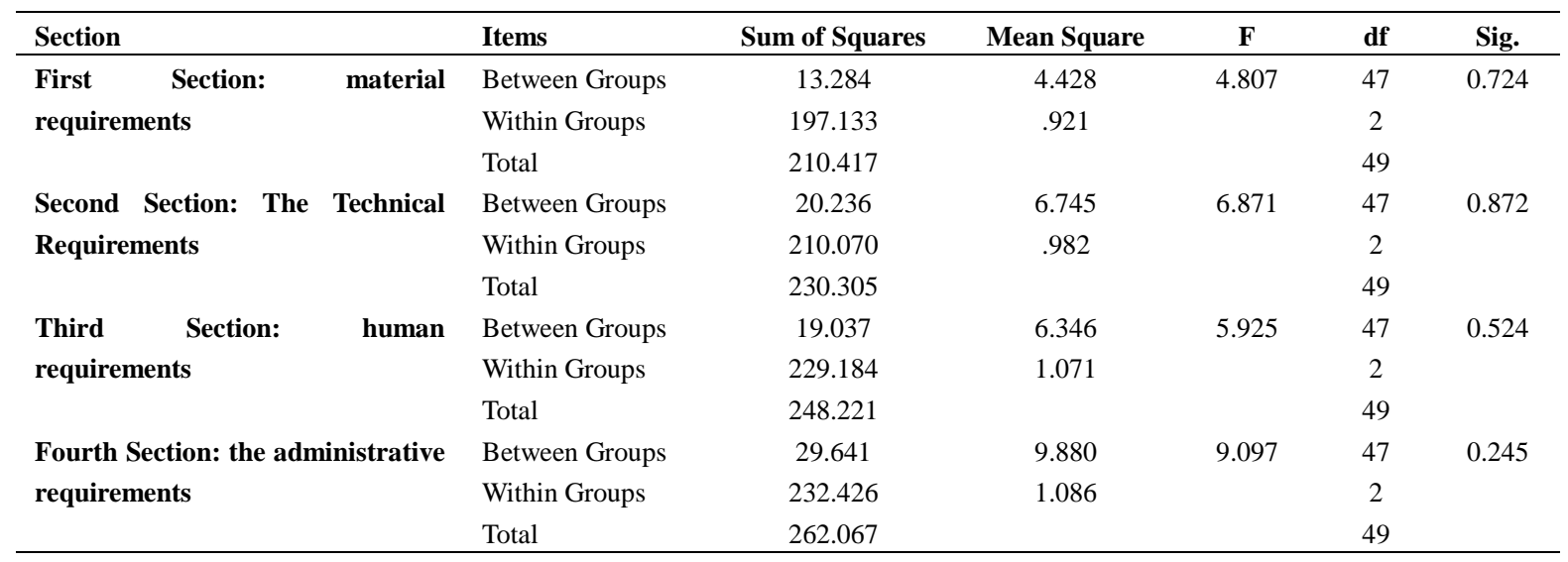


Table 10 shows that there are significant statistical differences at the level of significance $(\alpha \leq 0.05)$ for the application of computerized information systems to the Jordanian Companies from the viewpoint of its workers due to experience.

\section{Third: hypothesis}

$\mathbf{H O}_{3}$ : There are no differences at the level of significance $(\alpha \leq 0.05)$ for the application of computerized information systems to the Jordanian Companies from the viewpoint of its workers due to age.

In order to validate the hypothesis (Third hypothesis) test was performed (One Way ANOVA), the Table 11, shows that result.

Table 11. Test of hypothesis (third hypothesis) (one way ANOVA)

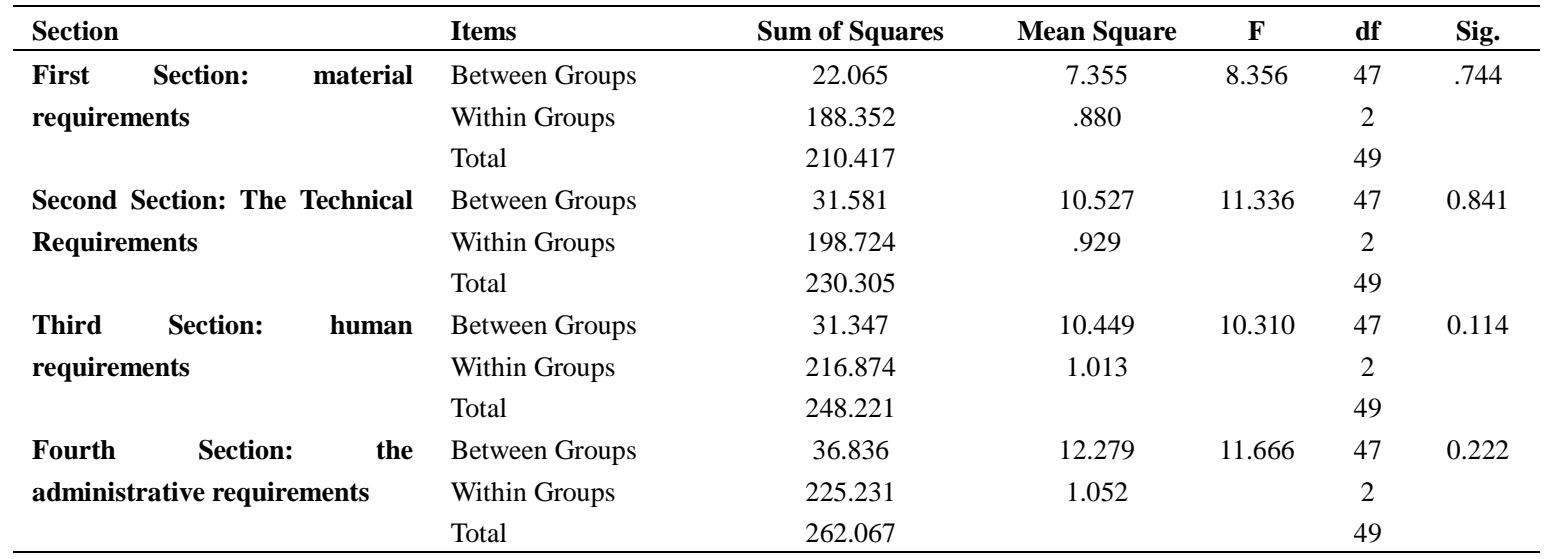

From the above table, it is noted that there are significant statistical differences at $(\alpha \leq 0.05)$ for the application of computerized information systems to the Jordanian Companies from the viewpoint of its workers due to age.

\section{Fourth: hypothesis}

$\mathbf{H O}_{4}$ : There are no impact at the level of significance $(\alpha \leq 0.05)$ on Computerized information system on Compliance to internal Control requirements according to ISA (315) from the standpoint of working for the Jordanian Companies.

In order to validate the hypothesis (fourth hypothesis) test was performed (Standard Multiple Regression Analysis).

Table 12. Test of hypothesis (fourth hypothesis)

(Standard Multiple Regression Analysis)

\begin{tabular}{cccccc}
\hline Beta & F Tabulated & $\mathbf{R}^{2}$ & $\mathbf{R}$ & Sig & Result of Ho \\
\hline 0.824 & 628.781 & 0.678 & 0.824 & $0.000^{*}$ & Reject \\
\hline
\end{tabular}

* significant at the level $(\alpha \leq 0.05)$.

Show data Table 16 that the level of significance (0.000) which is less than (0.05), and thus have a decision rule says accept the alternative hypothesis, if the level of significance (SIG) greater than (0.05), and we reject the hypothesis nihilism if the significance level less from (0.05), and through the previous table shows that the level of significance (SIG) is equal to (0.000), and since this level of significance is less than the level of (0.05) decision rule that "There are no impact at the level of significance $(\alpha \leq 0.05)$ on Computerized information system on Compliance to internal Control requirements according to ISA (315) from the standpoint of working for the Jordanian Companies".

\subsection{Baseline Data}

\subsubsection{Statistics and Data Analysis}

Were used a lot of statistical tests (such as t-test and also test variability Group. regression equation and show that there are no significant statistical differences at $(\alpha \leq 0.05)$ level between for the application of computerized 
information systems to the Jordanian Companies from the viewpoint of its workers depending on the demographic variables (gender, age and experience).

\section{Discussion}

The components of the study will be discussed through the presenting the most appropriate outcomes, findings and recommendations:

First: summary of the results of the study, by answering the questions of the study:

The first question: Are there significant statistical differences for the application of computerized information systems to the Jordanian companies from the employees' perspectives due to gender? (The answer to the first hypothesis).

Upon conducting the statistical analysis. The study found that: "there are no significant statistical differences at $(\alpha \leq 0.05)$ between for the application of computerized information systems to the Jordanian companies from the perspective of its workers that can be attributed to the demographic variables (gender)". This result is consistent with AL-Eqab and Ismail (2011) which did not show significant statistical differences that are attributed to the employees' gender, males and females are able to perform the tasks assigned to them and the dedication of mastery and there is no difference between the sexes.

Second question: Are there any significant statistical differences for the application of computerized information systems to the Jordanian Companies from the perspective of its workers due experience? (The answer of the second hypothesis)

The statistical analysis showed that: "that there are no significant statistical differences at $(\alpha \leq 0.05)$ for the application of computerized information systems to the Jordanian companies from the employees' perspectives due to the years of experience". This result is congruent to AL-Eqab and Ismail (2011) study which did not show significant statistical differences that can be attributed to the employees' years of experience.

The regulations, laws and accounting rules exist need to be able to use accounting systems, as the experience may not be essential in the event of the existence of these regulations and instructions.

Third question: There are no differences for the application of computerized information systems to the Jordanian companies from the perspective of its workers due to age? (The answer to the third hypothesis).

Through statistical analysis, the study concluded that: "there are no significant statistical differences at $(\alpha \leq 0.05)$ for the application of computerized information systems to the Jordanian companies from the employees' perspectives due to age". This result is consistent with the conducted by AL-Eqab and Ismail (2011), which it showed no differences that can be attributed to the age of employees.

The regulations, laws and accounting rules exist need to be able to use accounting systems, as the old may not be essential in the event of the existence of these regulations and instructions.

Forth question: Is there impact of Computerized information systems on Compliance to internal Control requirements according to ISA (315) from the perspectives of the employees who work for the Jordanian companies? (Represents the answer to the fourth hypothesis).

The study found significant statistical impacts of computerized information systems on compliance to internal control requirements according to ISA (315) from the perspectives of employees who work for the Jordanian companies". This result is consistent with Nayak et al. (2010), study, which showed that there are significant statistical difference between computerized information systems and the decision making process.

Which means that the greater the level of improvement (computerized information systems on compliance), Better they will (internal control requirements according to ISA (315)).

In light of the above findings, the study recommends the following:

1. Enactment laws and regulations which contribute in the effective use of computerized information systems at the Jordanian companies .

2. Develop programs and training courses that contribute in improving the skills of workers at the Jordanian companies in terms of computerized information systems.

3. Recruitment of computerized information systems in order to improve internal Control requirements according to ISA (315) at work.

4. Involve experienced and competent staff who are capable to use computerized information systems.

5. Create new programs and training workshops for the employees to deal appropriately with auditing through 
the use of computer software.

6 . The need for new research in the field of study conduct.

7. Disseminate the results of the study on the relevant sectors.

\section{Acknowledgments}

Thank the researcher who contribute to the preparation of this study, is also a teacher who arbitration resolution in Jordanian universities, as well as the analysis of statistical data.

\section{References}

Al-Eqab, M., \& Ismail, N. (2011). Contingency Factors and Accounting Informaiton System Design in Jordanian Companies. IBIMA Business Review, 9(11), 1-13. http://dx.doi.org/10.5171/2011.166128

Al-Mamary, Y. H., Shamsuddin, A., \& Aziati, N. (2014). Factors Affecting Successful Adoption of Management Information Systems in Organizations towards Enhancing Organizational Performance. American Journal of Systems and Software, 2(5), 121-126.

Brown, C. E., Wong, J. A., \& Baldwin, A. A. (2007). Discussion of Information Technology, Related Activities of Internal Auditors. Journal of Emerging Technologies in Accounting, (4), 1-28. http://dx.doi.org/10.2308/jeta.2007.4.1.1

Edwards, D., Kusel, J., \& Oxner, T. (2010). Discussion of Information Technology, Related Activities of Internal Auditors. Journal of Investment Compliance, 15(1), 4-63.

Karim, A. (2011). The Significance of computerized Information Systems for Enhancing Strategic And Tactical Planning. Journal of Information Systems and Technology Management, 8(2), 459-470. http://dx.doi.org/10.4301/S1807-17752011000200011

Laudon, K. C., \& Jane, P. (2009). Management Information Systems: Managing the Digital Firm (11th ed.). Prentice Hall/CourseSmart.

Miller, D. (2013). Measurement by the physical educator, Why and Low (3rd ed). Indianapolis, Indiana, WM. C. Brown Communication, INC.

Monika, J., \& Soral, G. (2010). Impact of ERP system on auditing and internal control. Research Journal of Social Science and Management. Retrieved from http://www.theinternationaljournal.org

Navaz, V. (2013). Concepts and Applications of Management Information Systems. Arabian Journal of Business and Management Review, 2(6), 6-15. http://dx.doi.org/10.12816/0002278

Nayak, G., Sequeira, A. H., \& Senapati, S. (2010). Management Information System for Effective and Efficient Decision Making: A Case Study. http://dx.doi.org/10.2139/ssrn.2174035

Salehi, M., \& Abdipour, A. (2011). A Study of The Barriers of Implementation of Accounting Informaion System: Case of Listed Compnies In Tehran Stock Exchange. Journal of Economies And Behavioral Studies, 2(2), 76-85.

Sayana, S., Vihelmson, B., \& Thulin, E. (2008). Using CAATs to Support IS Audi. Information Systems Control Journal, I(1), 125-126.

Sekaran, U., \& Bougie, R. (2013). Research Methods For Business: A Skill -Building Approach (6th ed.). John Wiley \& Sons, Inc.

Wei-hua, X. (2011). The Precaution of Enterprise Internal Control under the ERP System. International Conference on Business Computing and Global Informatization. http://dx.doi.org/10.1109/BCGIn.2011.11

\section{Appendix}

\section{Questionnaire}

\section{Dear Respondent...}

The researcher's is preparing a study titled: "The Impact of Computerized information systems on Compliance to internal Control requirements according to ISA (315) in Jordanian Companies". This questionnaire consists of two parts all of which you are kindly requested to answer.

The contents of this survey are absolutely confidential, The participant's identity and responses will not be disclosed under any circumstances. 


\section{Thank you for your kind cooperation.}

\section{Researcher}

\section{Part One : This part consists of general data on the respondent:}

\section{1-Gender :}

$$
\neg \text { Male }
$$

$\neg$ Female

\section{2- Number of year of experience:}

$$
\begin{array}{ll}
\neg \text { less than } 5 \text { years } & \neg \text { from } 5 \text { to } 10 \text { years } \\
\neg \text { from } 11 \text { to } 15 \text { years } & \neg 16-20 \text { years } \\
\neg \text { More than } 20 \text { years } &
\end{array}
$$

\begin{tabular}{|c|c|c|c|c|c|}
\hline Phrase & $\begin{array}{c}\text { Strongly } \\
\text { Agree } \\
\text { (5) }\end{array}$ & $\begin{array}{c}\text { Agree } \\
\text { (4) } \\
\end{array}$ & $\begin{array}{c}\text { Neutral } \\
\text { (3) }\end{array}$ & $\begin{array}{c}\text { Disagree } \\
\text { (2) }\end{array}$ & $\begin{array}{c}\text { strongly } \\
\text { Disagree } \\
\text { (1) }\end{array}$ \\
\hline \multicolumn{6}{|c|}{ First Section: material requirements } \\
\hline \multicolumn{6}{|c|}{\begin{tabular}{l|l|l} 
1. The Jordanian companies develop computer hardware to keep pace & \\
with the growing demands and needs of customers. &
\end{tabular}} \\
\hline \multicolumn{6}{|l|}{$\begin{array}{l}\text { 2-There are available appropriate accessory for computer hardware that } \\
\text { facilitate the nature of work. }\end{array}$} \\
\hline \multicolumn{6}{|l|}{$\begin{array}{l}\text { 3- Modern and high speed and quality are used in the Jordanian } \\
\text { companies. }\end{array}$} \\
\hline \multicolumn{6}{|c|}{ Second Section: The Technical Requirements } \\
\hline \multicolumn{6}{|c|}{ 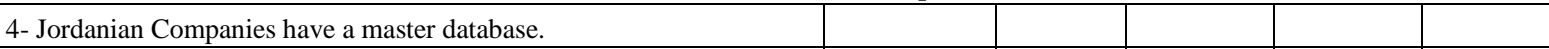 } \\
\hline \multicolumn{6}{|l|}{ 5- Availability of ready- made latest versions of the software. } \\
\hline \multicolumn{6}{|l|}{$\begin{array}{l}\text { 6- Programs are automatically continuously developed continuously in } \\
\text { collaboration with programming companies. }\end{array}$} \\
\hline \multicolumn{6}{|l|}{ 7-Latest versions of operating systems are available. } \\
\hline \multicolumn{6}{|l|}{$\begin{array}{l}\text { 8- Availability of the software needed to do the tasks of the job help in } \\
\text { performing administrative tasks. }\end{array}$} \\
\hline \multicolumn{6}{|l|}{ 9-Software security and protection available on modern computers. } \\
\hline \multicolumn{6}{|l|}{$\begin{array}{l}\text { 10- Jordanian Companies maintains a presence backup databases for all } \\
\text { information }\end{array}$} \\
\hline \multicolumn{6}{|c|}{$\begin{array}{c}\text { Third Section: human requirements } \\
\end{array}$} \\
\hline \multicolumn{6}{|l|}{$\begin{array}{l}\text { 11-There is a special division in the Jordanian Companies for the } \\
\text { maintenance of computerized information systems. }\end{array}$} \\
\hline \multicolumn{6}{|l|}{$\begin{array}{l}\text { 12-There are specialists who can provide solutions to the problems of } \\
\text { frequent users. }\end{array}$} \\
\hline \multicolumn{6}{|c|}{ Fourth Section: the administrative requirements } \\
\hline \multicolumn{6}{|l|}{$\begin{array}{l}\text { 13- Availability of computerized information systems provide all } \\
\text { required information in the various sections of Jordanian Companies. }\end{array}$} \\
\hline \multicolumn{6}{|l|}{$\begin{array}{l}\text { 14-Availability of computerized information systems provide } \\
\text { employees with all required information in a timely manner. }\end{array}$} \\
\hline 15- Information is constantly updated to satisfy the employees' needs. & & & & & \\
\hline
\end{tabular}

3-Age:

$$
\begin{aligned}
& \neg \text { less than } 25 \text { year } \\
& \neg \text { from } 25 \text { to } 34 \text { year } \\
& \neg \text { from } 35 \text { to } 44 \text { year } \\
& \neg \text { more than } 45 \text { year }
\end{aligned}
$$

\section{Part Two: Subject of Study:}

Please specify how far you agree that the following factors. By marking " $\sqrt{ }$ " in the square that is applicable to the statement. 
Fifth: Section: Internal control requirements according to ISA (315)

16- Standards contribute in the control of the surrounding environment.

17- It helps the organization in the process of risk assessment process.

18- The standard identification support information system.

19- The identification of standards control activities and monitoring of controls.

Any other suggestions:

\section{Copyrights}

Copyright for this article is retained by the author(s), with first publication rights granted to the journal.

This is an open-access article distributed under the terms and conditions of the Creative Commons Attribution license (http://creativecommons.org/licenses/by/4.0/). 